\title{
Low-velocity impact of hot-pressed PVA fiber-reinforced alkali-activated stone wool composites
}

\author{
(i) The corrections made in this section will be reviewed and approved by a journal production editor. \\ Valter Carvelli ${ }^{\mathrm{a}}$ ** valter.carvelli@polimi.it, Ana Veljkovic ${ }^{\mathrm{a}}$, Hoang Nguyen ${ }^{\mathrm{b}}$, Adeolu Adediran ${ }^{\mathrm{b}}$, Paivo Kinnunen ${ }^{\mathrm{b}}$, \\ Navid Ranjbar, ${ }^{\mathrm{c}, \mathrm{e}}$, Mirja Illikainen ${ }^{\mathrm{b}, * *}$ mirja.illikainen@oulu.fi \\ a'Department A.B.C., Politecnico di Milano, Piazza Leonardo Da Vinci 32, 20133, Milan, Italy \\ ${ }^{\mathbf{b}}$ Fibre and Particle Engineering Research Unit, University of Oulu, Pentti Kaiteran katu 1, 90014, Oulu, Finland \\ ${ }^{\mathbf{c}}$ Department of Mechanical Engineering, Technical University of Denmark, 2800, Kgs. Lyngby, Denmark \\ dDepartment of Health Technology, Technical University of Denmark, 2800, Kgs. Lyngby, Denmark \\ ${ }^{\mathbf{e}}$ Department of Civil, Environmental and Geomatic Engineering, University College London, London, WC1E \\ 6BT, UK \\ * Corresponding author. \\ ** Corresponding author.
}

\begin{abstract}
This study evaluates the effects of the manufacturing process and fiber reinforcement on low-velocity impact response of the recently developed PVA fiber-reinforced alkali-activated stone wool composites. To this end, reinforced and unreinforced specimens manufactured by hot-pressing were compared with those oven curing. The results revealed a similar impact response for the hot-pressed composite produced at $120{ }^{\circ} \mathrm{C}$ for $3 \mathrm{~h}$ and its counterpart cured at ambient pressure at $60{ }^{\circ} \mathrm{C}$ oven for $24 \mathrm{~h}$. Furthermore, fiber reinforcement significantly improves the impact resistance of the hot-pressed composites showing about a $50 \%$ increase in peak load and a $40 \%$ reduction in penetration compared to the unreinforced materials. In view of the development of the hot-pressed composites and potential applications, accurate predictive models are of extremely importance, hence the material mechanical behavior was here simulated by adopting the concrete damage plasticity model to predict the low-velocity impact response of both unreinforced and reinforced materials and successfully verified for the scaling-up purpose.
\end{abstract}

Keywords: Hot-pressing; Alkali-activated material; Mineral wool; Impact; Experimental testing; Finite element modeling

\section{Introduction}

The hot-pressing technique for alkali-activated materials (AAM) was introduced recently by Ranjbar et al. [1], to produce high-strength cementitious materials in a short time using a low amount of activation solution. This method uses a simultaneous combination of elevated temperature and high pressure to increase the dissolution of precursors [2], reduce pore content [1], and accelerate the condensation of reaction phases [2]. On one hand, using the high temperature increases the kinetic energy of the system and evaporates the non-structural water which in turn results in a higher concentration of the remaining activation solution, and therefore, enhances the dissolution of aluminosilicate precursors [3]. On the other hand, the induced pressure significantly densifies the matrix and changes the porosity structure of the material from a continuous network to small closed ones [3]. Hence, the combination of heating and 
pressing yields a high compressive strength of hot-pressed AAMs up to $\sim 160 \mathrm{MPa}$ shortly after the fabrication process $[1]$.

Despite the high mechanical properties, similar to other cementitious materials, hot-pressed AAMs exhibit brittle behavior leading to sudden failures. As a remedy, the previous study showed that incorporation of the polyvinyl alcohol (PVA) fiber leads to a significant enhancement in the quasi-static mechanical performance of the hot-pressed alkaliactivated stone wool composites with deflection hardening behavior [4]. However, due to the brittleness of the material, it is important not only to investigate the material properties under quasi-static loading conditions but also the responses of material at dynamic loading. In this line, it has already been shown that cementitious composites can exhibit different mechanical behavior when exposed to low- or high-velocity impact events [5-8]. Fibers have a significant role in the impact resistance of fiber-reinforced cementitious composites [9], which is influenced multiple factors such a type and shape of the fibers [10-13], fiber/matrix interaction, and distribution and orientation of the fibers [14]. Therefore, getting insights into the performance of fiber-reinforced hot-pressed AAMs under impact loading is of interest [15].

This research, therefore, investigated the low-velocity impact performance of the recently developed hot-pressed fiberreinforced alkali-activated composites exploiting recycled stone wool. In this line, the research had a twofold aim: (1) the experimental measurement of the hot-pressed AAMs mechanical response subjected to different impact energies, to demonstrate the efficiency of the reinforcement and the fabrication procedure; (2) the numerical prediction of the lowvelocity impact behavior using the concrete damage plasticity model, to assess its applicability and accuracy. The latter deserves much attention for these hot-pressed composites development and industrial scale-up, to get quick and accurate predictions of the mechanical response. A total of 4 different hot-pressed compositions were examined, namely fabricated at $100^{\circ}$ and $120^{\circ} \mathrm{C}$ with and without PVA fiber reinforcement. Furthermore, for comparison, the oven-cured mixtures with and without reinforcement were also tested as a reference.

\section{Materials and manufacturing}

Stone wool (SW) was used as the aluminosilicate precursor and obtained from Paroc (Saint Gobain Oy, Finland). The chemical composition of SW is shown in Table 1, as analyzed by X-ray fluorescence spectroscopy (XRF) using a PANalytical Omnian Axiosmax. Due to the fibrous nature of SW with a wide range of fibers length, and a very small bulk density, [Instruction: this sentence shoud be (see Revision 2):

..."it was challenging to grind the wool in a single step with a ball miller, to get the desired median particle size $\mathrm{d}_{50}$."]it was challenging to grind the wool in a single step. Therefore, the raw material was milled before its use according to the following steps. First, a portion of $200 \mathrm{~g}$ of SW was milled for $15 \mathrm{~min}$ at a speed of $6000 \mathrm{rpm}$ in a $10 \mathrm{~L}$ chamber with a ball filling ratio of $11 \%$. Afterward, the same portion of SW was added into the chamber repeating five times and milled in the same conditions with the previous step. The particle size distribution of milled SW was checked by the laser diffraction method with a Fraunhofer model [16] for every batch of milled SW. The particle size distribution of the milled SW is shown in Fig. 1, in which the targeted median particle size $\mathrm{d}_{50}$ was about $10 \mu \mathrm{m}$.

alt-text: Table 1

Table 1

(i) The table layout displayed in this section is not how it will appear in the final version. The representation below is solely purposed for providing corrections to the table. To preview the actual presentation of the table, please view the Proof.

Oxide composition of SW measured by XRF. ${ }^{\text {a }}$ Loss on ignition at $950{ }^{\circ} \mathrm{C}$.

\begin{tabular}{|c|c|c|c|c|c|c|c|c|c|c|}
\hline Oxide composition & $\mathrm{Na}_{2} \mathrm{O}$ & MgO & $\mathrm{Al}_{2} \mathrm{O}_{3}$ & $\mathrm{SiO}_{2}$ & $\mathrm{CaO}$ & $\mathrm{Fe}_{2} \mathrm{O}_{3}$ & $\mathrm{~K}_{2} \mathrm{O}$ & $\mathrm{MnO}$ & Others & $\mathrm{LOI}^{\mathrm{a}}$ \\
\hline wt $\%$ & 1.3 & 11.6 & 15.4 & 38.9 & 18.3 & 11.1 & 0.4 & 0.2 & 2.8 & 1.7 \\
\hline
\end{tabular}




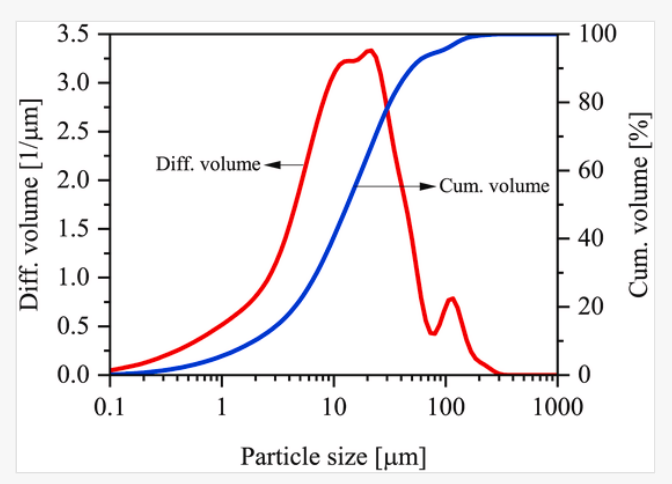

Particle volume distribution including diffraction and cumulative volume of ground SW.

PVA fibers manufactured by Kuraray (Japan) were used as reinforcement. The physical and mechanical properties of the fiber are detailed in Table 2. The fiber volume fraction of $2 \%$ and mix composition were used as adopted in the previous study [4]. Fine sand (FS) was used as aggregate (median size $100 \mu \mathrm{m}$ ) and obtained from milling standard sand (EN-196) for $1 \mathrm{~h}$ at $6000 \mathrm{rpm}$ with a filling ratio of $60 \%$. These values were used to have a uniform fiber dispersant, and thus, fabrication of homogenous composite, as discussed in Ref. [17]. A naphthalene sulfonate-based superplasticizer (name: Mighty 100, provided by KAO, Japan; and here denoted as M100) was used, which worked as a powdered chemical. This superplasticizer is appropriate for the alkali-activated system, according to preliminary experiments.

alt-text: Table 2

Table 2

(i) The table layout displayed in this section is not how it will appear in the final version. The representation below is solely purposed for providing corrections to the table. To preview the actual presentation of the table, please view the Proof.

Mechanical and physical properties of PVA fiber.

\begin{tabular}{|l|l|l|l|l|}
\hline $\begin{array}{l}\text { Elastic's modulus } \\
\text { (GPa) }\end{array}$ & $\begin{array}{l}\text { Elongation at break } \\
(\mathbf{\%})\end{array}$ & $\begin{array}{l}\text { Tensile strength } \\
(\mathbf{M P a})\end{array}$ & $\begin{array}{l}\text { Length } \\
(\mathbf{m m})\end{array}$ & $\begin{array}{l}\text { Diameter } \\
(\boldsymbol{\mu m})\end{array}$ \\
\hline 41 & 6 & 1600 & 8 & 40 \\
\hline
\end{tabular}

The mortar for the specimens was made according to the following steps. A $5 \mathrm{M}$ sodium hydroxide $(\mathrm{NaOH})$ solution was prepared by mixing $\mathrm{NaOH}$ pellets (supplied by VWR Finland) and deionized water for 10 min and cooled the mixture down to room temperature in a sealed plastic bottle for at least $24 \mathrm{~h}$ before the use. Separately, the SW, superplasticizer M100, and FS were mixed in a Kenwood 5 L mixer at low (100 rpm) and high (200 rpm) speed for 1 min each level. The alkaline solution was gradually added to the dry materials and mixed for 1 min at low and $2 \mathrm{~min}$ at high speeds. For the mortar with reinforcement, PVA fibers were added gradually during 15 min mixing period at high speed to prevent fiber clutching and balling in mortars. The finished mortar was cast in an oiled mold. The mix recipes of plain and reinforced compositions are shown in Table 3.

alt-text: Table 3

Table 3

(i) The table layout displayed in this section is not how it will appear in the final version. The representation below is solely purposed for providing corrections to the table. To preview the actual presentation of the table, please view the Proof.

The mix weight proportion of the alkali-activated SW. ${ }^{\mathrm{a}}$ wt. $\%$ of the binder; ${ }^{\mathrm{b}}$ vol $\%$ of mortar $(\mathrm{SW}+\mathrm{FS}+\mathrm{Activator}+\mathrm{M} 100)$.

\begin{tabular}{|c|c|c|c|c|c|}
\hline Mixture & SW & FS & NaOH 5 M & $\operatorname{M100}(w t . \%)^{a}$ & PVA fiber (vol\%) \\
\hline Plain mixture & 1 & 0.3 & 0.65 & 0.5 & - \\
\hline
\end{tabular}


After casting into the mold, mortars were hot-pressed with a Fontijne Presses (LABECON 300, the Netherlands). The mold was cured between two plates in the machine for $3 \mathrm{~h}$ at $100{ }^{\circ} \mathrm{C}$ or $120{ }^{\circ} \mathrm{C}$ subjected to a fixed pressing force of $60 \mathrm{kN}$ ( $\sim 25 \mathrm{MPa}$ on samples). The pressing temperatures were chosen to be quite lower than the onset of PVA degradation (i.e., roughly $180^{\circ} \mathrm{C}$ [18]), and after preliminary measurements with several coupling of pressing time and temperature. The two temperatures, here adopted, have been selected giving the best quasi-static mechanical performance [4].

In addition, a set of samples was cured in the oven for the sake of comparison with the hot-pressed ones. The ovencured mixtures were vibrated for $3 \mathrm{~min}$ at $1 \mathrm{~Hz}$ and cured at $60{ }^{\circ} \mathrm{C}$ for $24 \mathrm{~h}$.

After demolding (i.e., $3 \mathrm{~h}$ for hot-pressed samples and $24 \mathrm{~h}$ for oven-cured samples), both hot-pressed and oven-cured samples were stored in plastic bags at room temperature. Impact mechanical tests of all mixtures were conducted after 28 days. The sample IDs are listed in Table 4.

alt-text: Table 4

Table 4

(i) The table layout displayed in this section is not how it will appear in the final version. The representation below is solely purposed for providing corrections to the table. To preview the actual presentation of the table, please view the Proof.

The sample IDs used in this study.

\begin{tabular}{|c|c|c|c|c|c|c|}
\hline \multirow{3}{*}{ Curing } & \multicolumn{3}{|c|}{ PVA fiber reinforced composites } & \multicolumn{3}{|c|}{ Unreinforced composites } \\
\hline & $120^{\circ} \mathrm{C}$ & $100^{\circ} \mathrm{C}$ & $60^{\circ} \mathrm{C}$ & $120^{\circ} \mathrm{C}$ & $100{ }^{\circ} \mathrm{C}$ & $60^{\circ} \mathrm{C}$ \\
\hline & $3 \mathrm{~h}$ & $3 \mathbf{h}$ & $24 \mathrm{~h}$ & $3 \mathrm{~h}$ & $3 \mathrm{~h}$ & $24 \mathrm{~h}$ \\
\hline Hot-press & PVA-120-3 & PVA-100-3 & & $120-3$ & $100-3$ & \\
\hline Oven & & & PVA-60-24 & & & $60-24$ \\
\hline
\end{tabular}

\section{Experimental features and devices}

A CEAST FractoVis 6789 was used as a drop weight device with a hemispherical striker tip of 20 mm diameter to evaluate the impact performance of the specimens. Preliminary tests with different impact energy levels were considered to detect the perforation energy. Then, two energy levels, lower than the perforation one, were selected to observe the damage imparted during impact. The impactor had a mass of $3.153 \mathrm{~kg}$. The specimen $\left(75 \times 75 \mathrm{~mm}^{2}\right.$, and thickness $15 \mathrm{~mm}$ ) was clamped by a system with an inner hole diameter of $40 \mathrm{~mm}$ and impacted at the center. The rebound catcher system was enabled to stop the impactor during its second descent. At least three specimens for each material and energy level were tested.

To assess the damage imparted during impact, the morphology of the impacted surface $\left(60 \times 60 \mathrm{~mm}^{2}\right)$ was detected by a shape measurement laser device, with a step movement of $0.2 \mathrm{~mm}$ and a sensitivity of $0.001 \mathrm{~mm}$. Measurements of two specimens for each material were adopted to get the dent depth.

\section{Experimental results}

To compare the impact performance and observe the damage imparted by impact, the perforation energy was first detected, and then two lower energy levels were selected, namely: $10 \mathrm{~J}$ and $20 \mathrm{~J}$ for PVA reinforced composites; $5 \mathrm{~J}$ and $10 \mathrm{~J}$ for unreinforced composites, see Fig. 2. Those energy levels were adjusted by varying the impactor drop height, e.g., $0.162 \mathrm{~m}(5 \mathrm{~J}), 0.323 \mathrm{~m}(10 \mathrm{~J})$, and $0.647 \mathrm{~m}(20 \mathrm{~J})$. The recorded impactor velocity at the initial contact was: $1.78 \mathrm{~m} / \mathrm{s}(5 \mathrm{~J}), 2.52 \mathrm{~m} / \mathrm{s}(10 \mathrm{~J}), 3.57 \mathrm{~m} / \mathrm{s}(20 \mathrm{~J})$. These values are considered as low-velocity impact events (see e.g. [19] for impact of concrete). 

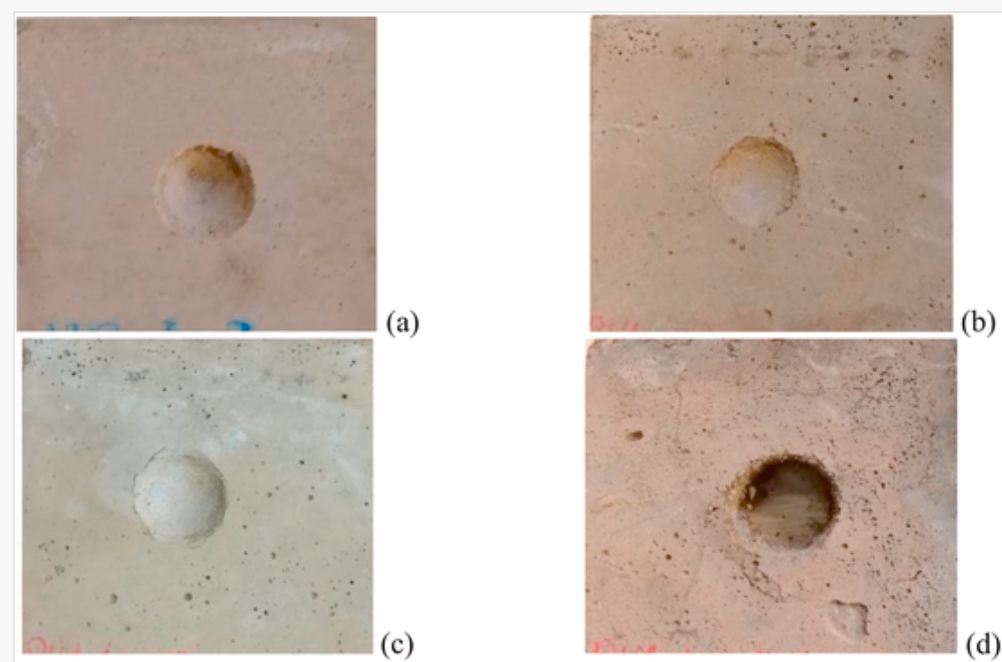

Hot-pressed specimens after the impact test: (a) unreinforced specimen 120-3 subjected to $10 \mathrm{~J}$; reinforced specimen PVA-120-3 subjected to (b) $10 \mathrm{~J}$, (c) $20 \mathrm{~J}$ and (d) perforation.

Fig. 3 shows the evolution of the force and energy during the time of impact as well as the force as a function of the impactor penetration at the perforation of both hot-pressed and oven-cured unreinforced and reinforced composites. The initial linear part of the force-penetration curve had a similar slope for both unreinforced and reinforced composites up to $\sim 800 \mathrm{~N}$, above this value, a variation of the slope indicated the initiation of the damage. At this load level, the unreinforced composites had a higher reduction of stiffness compared to the reinforced counterparts. This additional load carrying capacity is due to the presence of the PVA fibers causes toughening mechanisms, e.g., crack bridging, fiber pull-out and crack branching, which increases the fracture energy and delays the development of crack formation [ $14,15]$. Such interaction at micro scale of the matrix and the reinforcement, as well as the microstructure and reaction product of the hot-pressed AAMs, was studied in Ref. [4] for the same composites. A schematic overview of the fibers role during impact is[Instruction: Add the following sentence after "...is depicted in Fig. 4." (see Revision 2):

"It is noteworthy that the effect of high alkalinity (with $\mathrm{NaOH} 5 \mathrm{M}, \mathrm{pH}>14$ ) on PVA fibers could be detrimental for the interaction of reinforcement and matrix. It is a considerable aspect needing future study to gain in-depth insights into the interfacial properties between the fibers and hot-pressed AAM matrix."] depicted in Fig. 4.

alt-text: Fig. 3

Fig. 3 


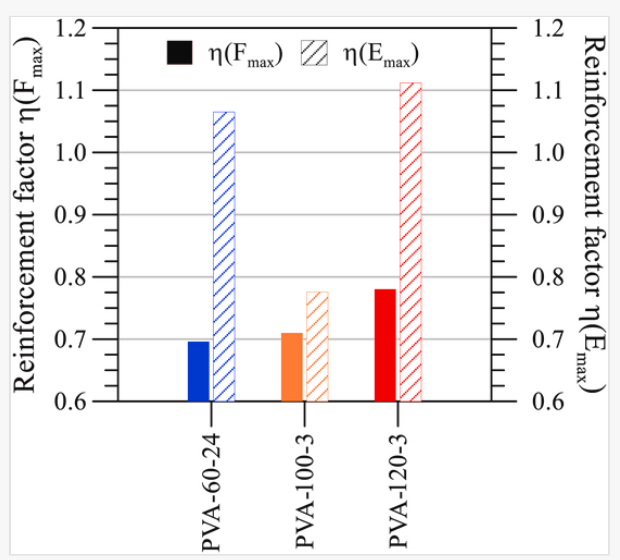

Impact tests at perforation: reinforcement factor for the maximum force and absorbed energy.

The behavior of the materials subjected to two levels of impact energy lower than the perforation value was studied to compare the imparted damage. Figs. 6a-9a highlighted that the impact energy was absorbed entirely and dedicated to damage the material.

alt-text: Fig. 6

Fig. 6
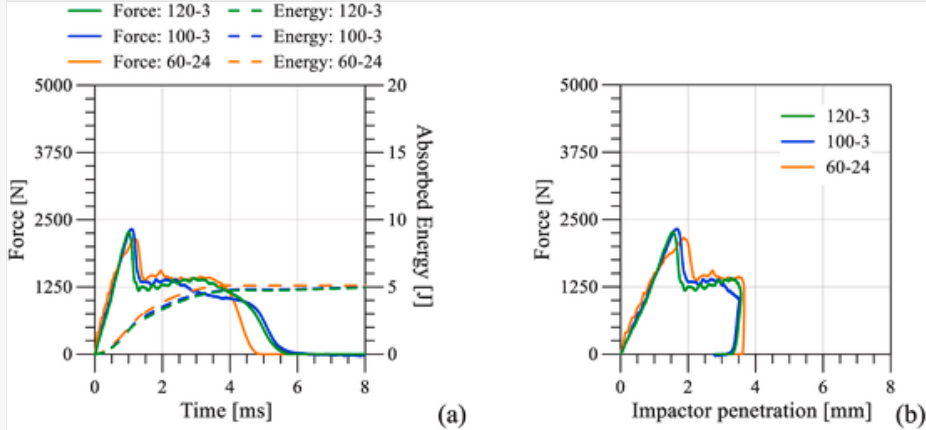

Impact tests of plain materials, $5 \mathrm{~J}$ : representative curves (a) force and energy vs. time; (b) force vs. impactor penetration.

alt-text: Fig. 7

Fig. 7
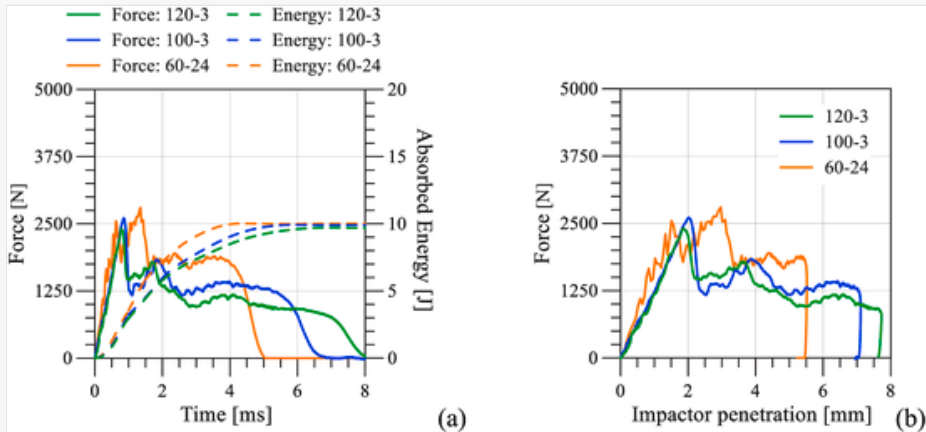


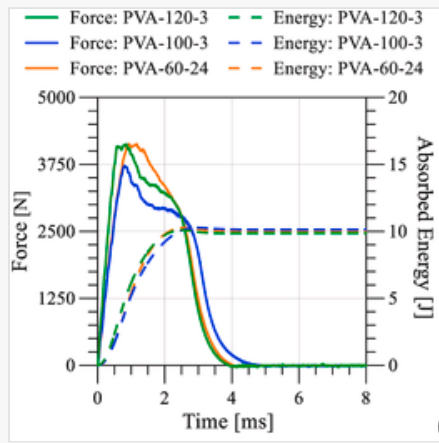

(a)

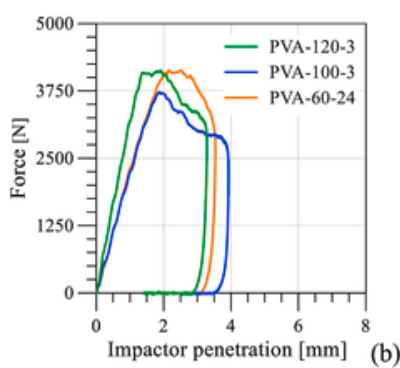

Impact tests of reinforced materials, $10 \mathrm{~J}$ : representative curves (a) force and energy vs. time; (b) force vs. impactor penetration.

alt-text: Fig. 9

Fig. 9
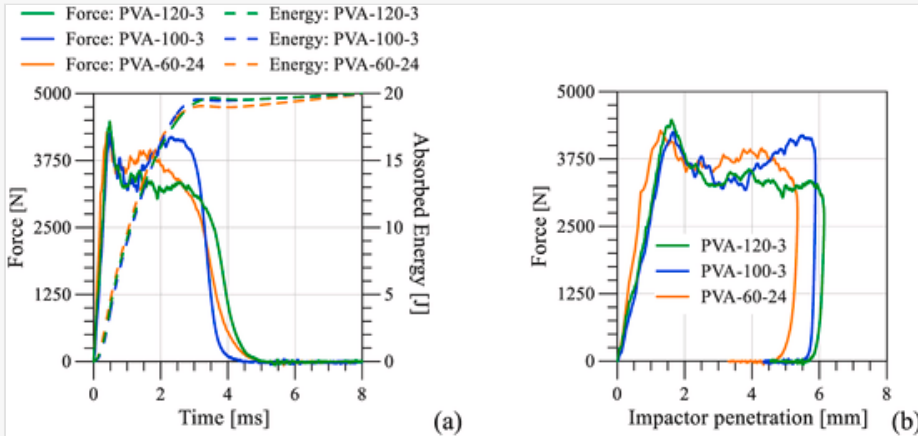

Impact tests reinforced materials, $20 \mathrm{~J}$ : representative curves (a) force and energy vs. time; (b) force vs. impactor penetration.

Fig. $6 \mathrm{a}$ and $\mathrm{b}$ show that at an impact energy of $5 \mathrm{~J}$ unreinforced materials have a similar response to both force evolution and penetration, respectively. This indicates that the proposed fabrication processes have a negligible influence on the material behavior at low-level impact energies (see also comparison in Fig. 10b).

When the impact energy was increased to $10 \mathrm{~J}$, the maximum force and penetration of unreinforced specimens were increased by $\sim 15 \%$ and $48 \%$, respectively, compared to specimens subjected to the $5 \mathrm{~J}$ impact, see also Fig. 10c. At this energy level, the difference in the fabrication process was observed, and oven cured material showed a more brittle behavior with a reduction in maximum impactor penetration (Fig. 10c), namely in the capacity to deform 'plastically' ( Fig. 7b), in comparison with the hot-pressed ones.

alt-text: Fig. 10 

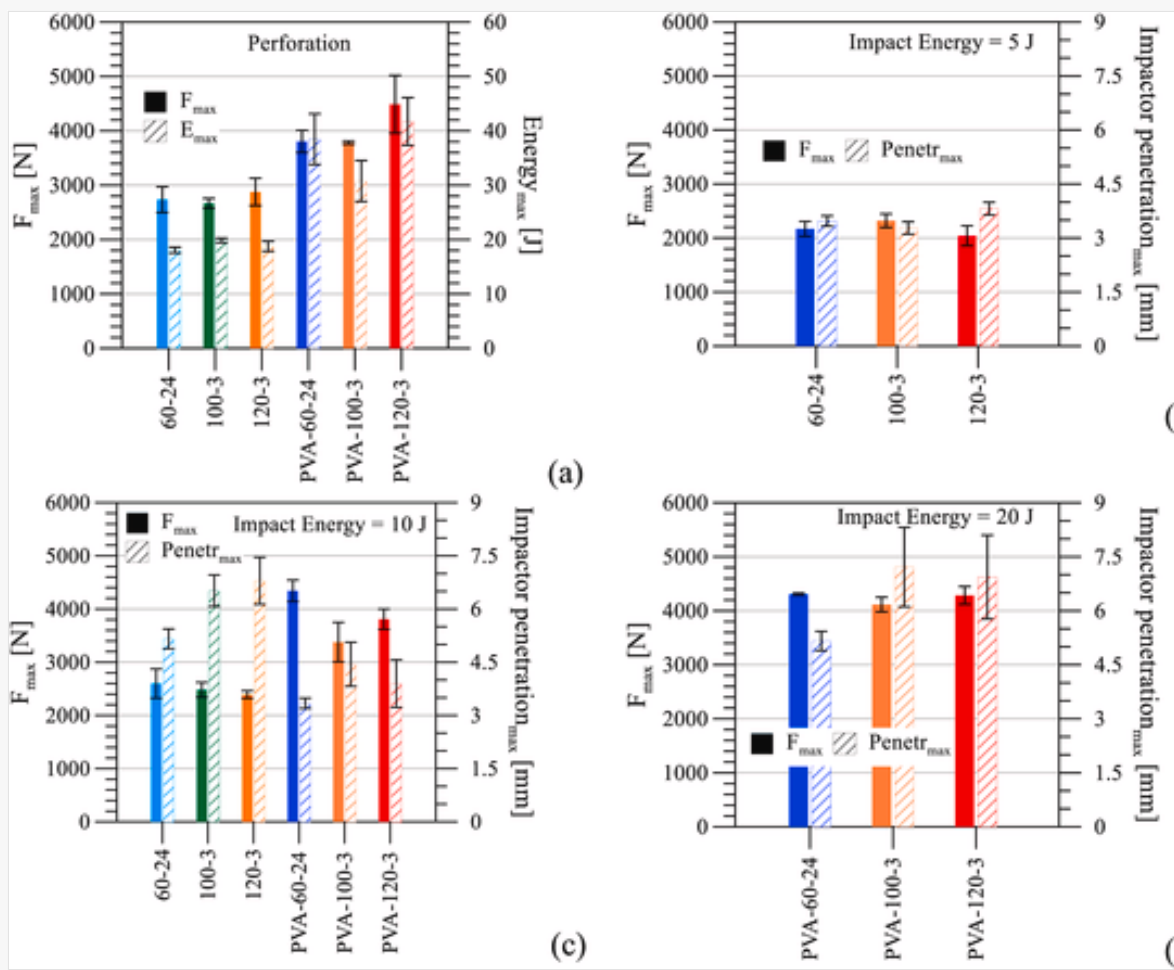

(a)

(b)

deviation (error bar) of three measurements.

For the impact energy of $10 \mathrm{~J}$, the PVA reinforced composites showed about 50-65\% increase in the maximum force and $30-40 \%$ reduction in penetration compared with the unreinforced specimens, see Fig. 8 and Fig. 10c. This is due to the strong adhesion between the fiber and matrix, which increases the energy absorption from the cracking of the matrix, fiber/matrix debonding and fiber sliding [21], while reduces the cracks propagation, by fiber bridging, leading to a decrease of permanent deformation. A similar dynamic crack growth resistance was observed in fiber-reinforced concrete [14].

The effect of the fabrication process is shown in Fig. 8. It was of interest that the hot-pressed PVA-120-3 and the ovencured PVA-60-24 composites had quite similar performance, while the hot-pressed PVA-100-3 had $\sim 20 \%$ lower maximum force and $\sim 20 \%$ higher maximum penetration (see the comparison in Fig. 10c). This is due to the fact that the thermal energy of the system for PVA-100-3 specimens is lower to remove the large fraction of free water that in turn, remains in the matrix as porosity $[2,3]$.

The impact of the reinforced composite with a higher energy of $20 \mathrm{~J}$ (Fig. 9) did not indicate a considerable influence of the fabrication process on the maximum impact force (Fig. 10d), while a 30\% reduction of the impactor penetration was observed in the oven-cured specimens compared with the hot-pressed counterparts.

The morphology of specimens' surface, impacted with an energy of $10 \mathrm{~J}$, is depicted in Fig. 11 for unreinforced materials, and in Fig. 12 for reinforced composites. As detected with the penetration of the impactor (Fig. 10), the PVA fibers drastically reduced the extension of the damaged zone. It is quantitatively comparable considering the dent depth (Fig. 13), namely the maximum residual depth of the impacted area. To this end, the dent depth of the materials with PVA fibers was almost 58\% lower than the unreinforced counterpart. It confirmed the positive effect of the bridging action of the fiber reinforcement, which helped to transfer the load between fibers and matrix, delayed cracks propagation, and consequently, enhanced the impact load-carrying capacity and reduced the damage diffusion. The effect of the curing process on the dent depth recalled, as expected, the same trend mentioned for the impactor penetration at different energy levels (see Figs. 10 and 13). The slightly lower value of the dent depth comparing to the impactor penetration could be related to the more precise laser device and a possible slight recovery during the few days between the impact and the measurement. For the considered impact energies, the oven-cured material (with and without reinforcement) had a smaller dent, and the variation to the hot-pressed composites increased with increasing impact energy. The comparison still highlighted the capacity of the hot-pressed composites to absorb the impact with a higher level of 'plastic' deformation. 
Fig. 11
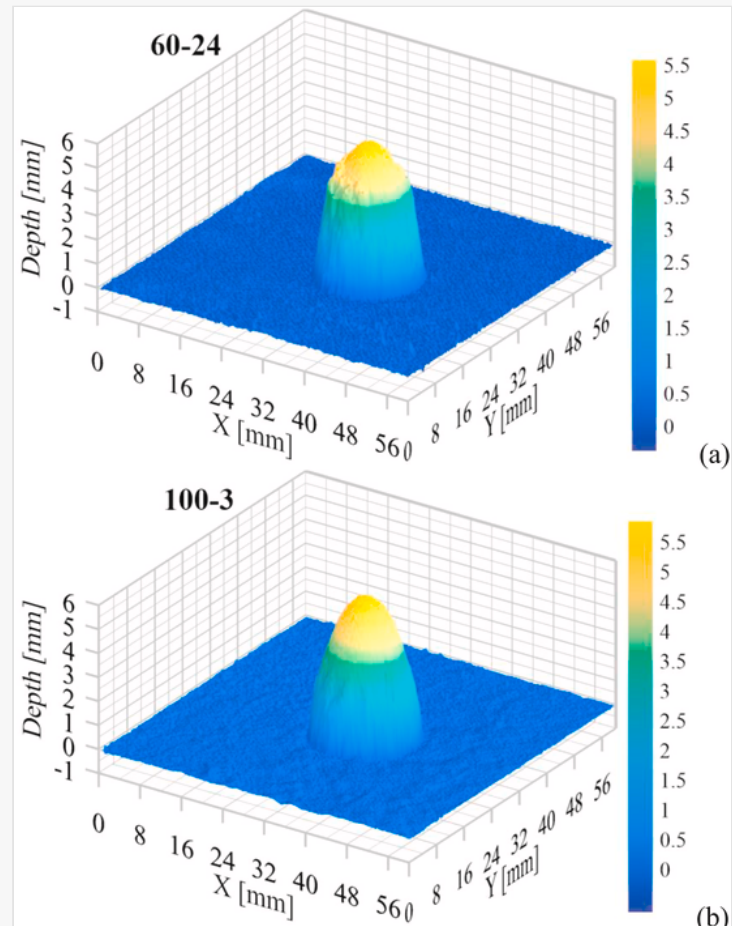

(a)

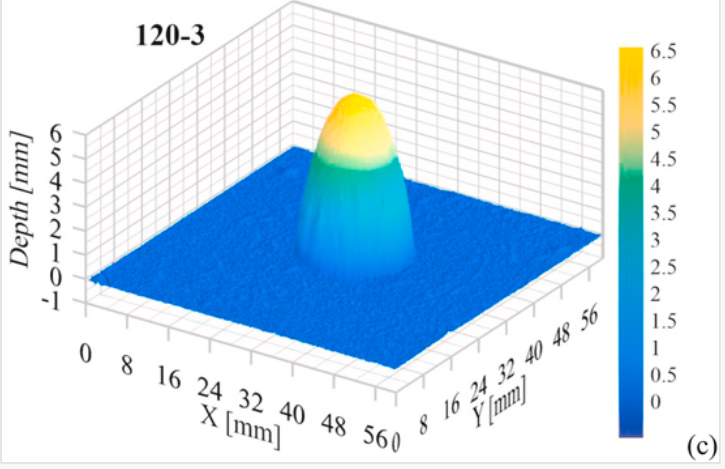

Impact tests, representative laser profiles for impact energy $10 \mathrm{~J}$ of plain materials: (a) 60-24; (b) 100-3; (c) 120-3.

alt-text: Fig. 12

Fig. 12 

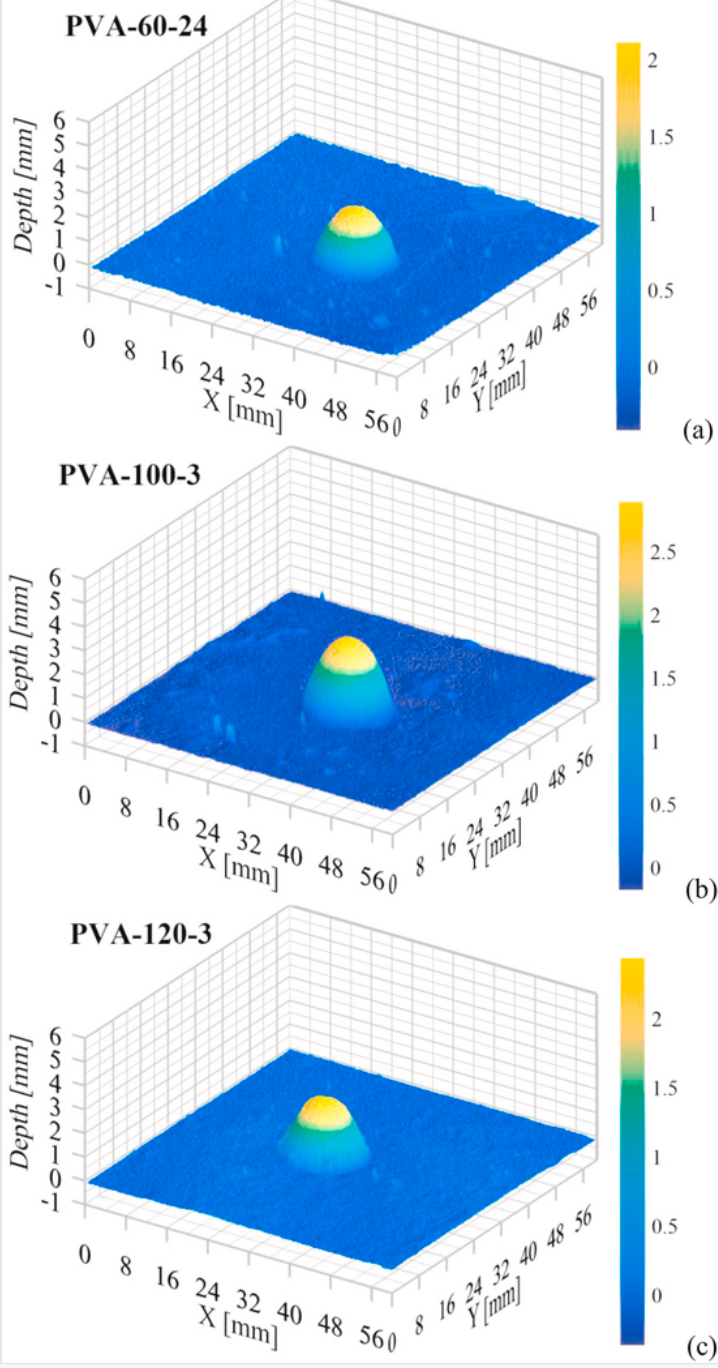

Impact tests, representative laser profiles for impact energy $10 \mathrm{~J}$ of reinforced materials: (a) PVA-60-24; (b) PVA-100-3; (c) PVA-120-3.

alt-text: Fig. 13

Fig. 13 

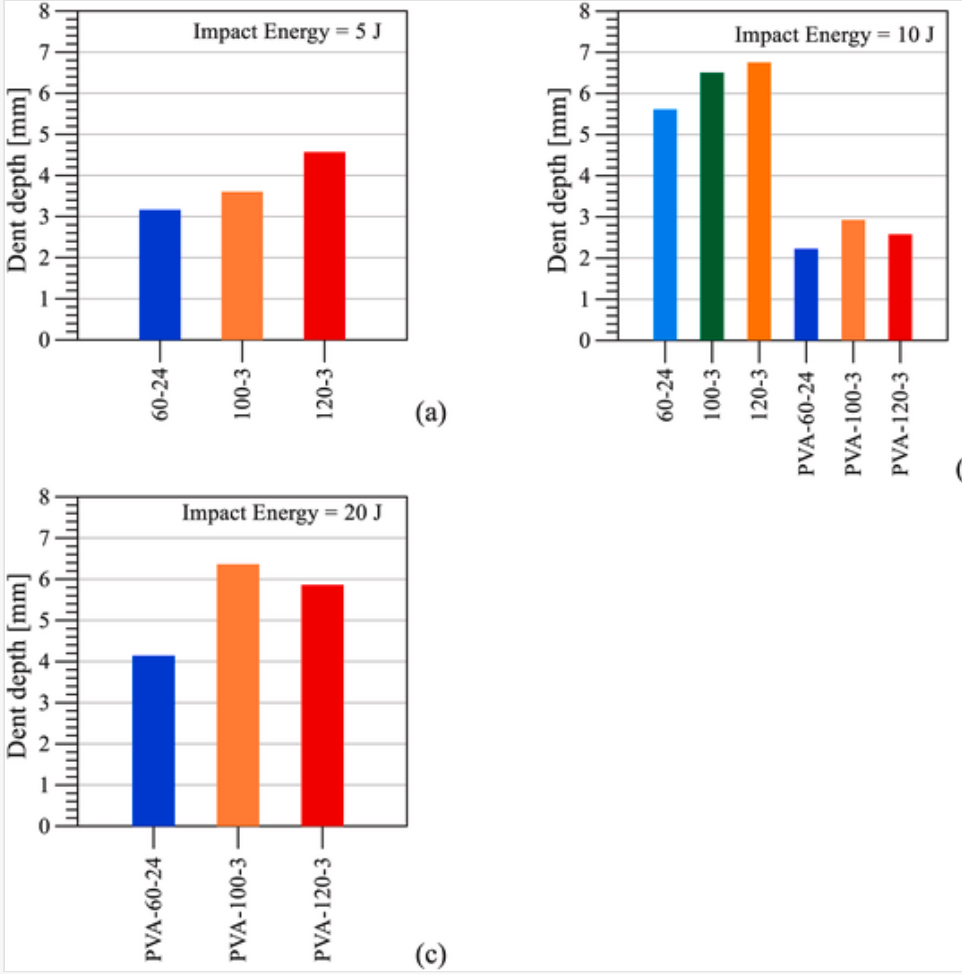

(c)

Impact tests: dent depth by laser measurements: (a) impact energy $5 \mathrm{~J}$; (b) impact energy $10 \mathrm{~J}$; (c) impact energy $20 \mathrm{~J}$. Average of two measurements.

\section{Numerical modeling}

A dedicated constitutive model for numerical mechanical predictions is not available for the considered hot-pressed composites. Hence, the finite element method (FEM) is here exploited considering an available constitutive model adapted to consider the peculiarities of the studied hot-pressed materials. Numerical modeling of the impact experimental tests was performed using Abaqus Explicit software [22]. Four hot-pressed materials were selected for the numerical simulation, namely 100-3 and 120-3 (impact energy $10 \mathrm{~J}$ ), PVA-100-3 and PVA-120-3 (impact energy $20 \mathrm{~J}$ ).

The widespread material models for the simulation of concrete behavior under impact loading (see e.g. Ref. [23-26]) consider the strain rate effect on material compressive and tensile behavior. In this study, the material constitutive behavior was simulated with the concrete damage plasticity (CDP) model [22], which does not include such effects and is mainly dedicated to quasi-static and cyclic loading conditions [22]. The reasons for this selection are: unavailable measurements of the strain rate effect on the properties of the considered materials; the impact velocities (see Section 4), which are lower than the ones in other studies on concrete in which strain rate effect was neglected (see e.g. Ref. [19], impact velocity in the range of 3.7-9.3 $\mathrm{m} / \mathrm{s}$ ); and the strain rate levels, which were estimated by the simulations in the range of 35-75 s ${ }^{-1}$, namely at the boundary between dynamic and impact loadings in the model code for concrete structures [27]. However, future experimental study will be dedicated to measure the strain rate effect on the mechanical properties of the considered AAMs to refine the numerical predictions.

As for the input parameters, some assumptions and approximations were introduced, due to unavailable experimental measurements. The dilation angle $\psi$, in the CDP model, was adopted to be $30^{\circ}$ [28], being the lower value of the typical range $30^{\circ}-45^{\circ}$. The remaining set of CDP parameters was assumed as suggested in [22], that is, flow potential eccentricity $\varepsilon=0.1$, the ratio of initial equibiaxial compressive yield stress to initial uniaxial compressive yield stress 
$\sigma_{b 0} / \sigma_{c 0}=1.16$, the ratio of the second stress invariant on the tensile meridian to that on the compressive meridian $K_{c}=0.67$, and viscosity parameter $\mu=0$.

The behavior under uniaxial compression was measured experimentally [4], and it was adopted as stress-strain law (see Fig. 14a). The modulus of elasticity was estimated as the slope of the linear part of the compressive stress-strain curve ( Fig. 14a). Poisson's ratio was adopted as 0.3 .

alt-text: Fig. 14

Fig. 14

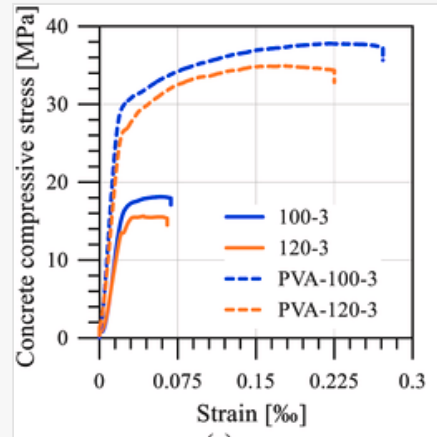

(a)

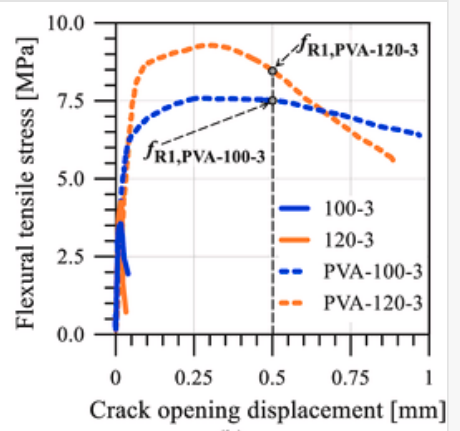

(b)

Experimental (a) compressive stress-strain, (b) flexural tensile stress vs. crack opening displacement (COD) curves.

Tensile properties of materials were experimentally obtained using four-point bending tests [4], providing flexural tensile stress vs. crack opening displacement (COD) curves (Fig. 14b). Results of flexural tests were used as an input for estimating axial tensile stress-crack opening law. Although the adopted relationships are intended for scaled-up concrete samples, they were used herein for the lack of dedicated mechanical models to the present materials. Relations between flexural and indirect tensile strengths for concrete, proposed by Hammitt [29] and Balbo [30], were used herein (Eq. (1) and (2), respectively).

$$
f_{c t, f}=1.02 f_{c t, s p}+1.48[\mathrm{MPa}]
$$

$$
f_{c t, f}=1.16 f_{c t, s p}+1.30[\mathrm{MPa}]
$$

In Eqs. (1) and (2), $f_{c t, f}$ is flexural tensile strength, and $f_{c t, s p}$ is indirect (splitting) tensile strength. Indirect tensile strength is estimated as an average of the values $f_{c t, s p}$ obtained from the two equations. Subsequently, the axial tensile strength was taken as 0.9 of indirect tensile strength, according to Ref. [31]. The tensile behavior of all materials was modeled as linear up to the axial tensile strength, whereas post-peak stress - crack opening law was estimated differently for plain, and PVA reinforced materials. For plain materials, fib Model Code 2010 (MC2010) [27] suggestions were adopted for defining the shape of post-peak law and estimating the tensile fracture energy (Fig. 15). Since these parameters were not measured experimentally, Model Code 2010 recommendations for concrete were used. The bi-linear post-peak law was calibrated using the tensile fracture energy, 30\% increased as allowed by [27]. Modeling the tensile post-peak behavior of PVA reinforced materials was according to the proposal in Ref. [32]. Although that reference was mainly dedicated to the modeling of steel fiber-reinforced concrete, it was used in the present study to similarly estimate the tensile post-peak behavior of the considered PVA-reinforced materials. The first leg of this bi-linear law was modeled following the MC2010 [27] proposal for the plain concrete. The second leg needed calibration of some additional parameters, as detailed in Ref. [32]. Post-cracking residual strength at $\mathrm{COD}=0.5 \mathrm{~mm}, f_{R 1}$, was taken from the experimental flexural test (Fig. 14b). By adopting parameter $k_{a}=0.37$ and shifting the value of $f_{F t s}=k_{a} k_{a} f_{R 1}$ (serviceability residual strength) at zero crack opening [32], the first point of the second leg line was defined. Then, post-cracking residual strength at $\mathrm{COD}=2.5 \mathrm{~mm}, f_{R 3}$, was estimated by assuming 
the ratio $f_{R 3} / f_{R 1}=0.5$. By adopting parameter $k_{b}=0.529-0.143 \frac{f_{R 3}}{f_{R 1}}$ and the value of $f_{F t, 2.5}=0.5 f_{R 3}-\frac{k_{b}}{2} f_{R 1}$ (residual strength at the crack opening of $2.5 \mathrm{~mm}$ ) another point of the linear second leg was defined. Finally, the first and the second legs of this bi-linear law were completely defined by their intersection point, and thus, a complete axial tensile stress-crack opening curve was implemented in the numerical model (Fig. 15).

alt-text: Fig. 15

Fig. 15

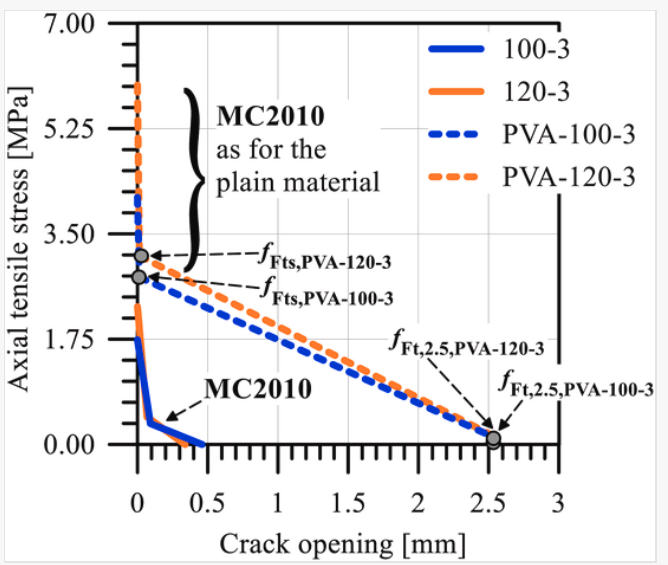

Axial tensile stress vs. crack opening curves.

One-quarter of the experimental specimen geometry, using two planes of symmetry, was modeled for decreasing the calculation time (Fig. 16). The impact simulation was conducted by the Abaqus Dynamic Explicit module [22]. The specimen was constrained to fulfill the symmetries and the support as in the test device, while the impactor was modeled considering the symmetries and assigning a velocity corresponding to the considered impact energy. The density of the impactor was such as to simulate the weight of the complete loading device, thus attaining the value of the experimental impact energy. Both impactor and specimens were modeled with 3D solid hexahedral elements C3D8R, with reduced integration. FE mesh of the specimen was denser, with a length of element side of approximately $1 \mathrm{~mm}$, whereas the impactor ball mesh was coarser (Fig. 16). The total number of elements was 26,827. The latter resulted from a mesh sensitivity analysis to get the proper balance between simulation time and accuracy of the outcomes. The contact of specimen and impactor was modeled considering a surface-based hard contact [22] in the normal direction and a frictional contact in the tangential ones, assuming a friction coefficient of 0.1.

alt-text: Fig. 16

Fig. 16

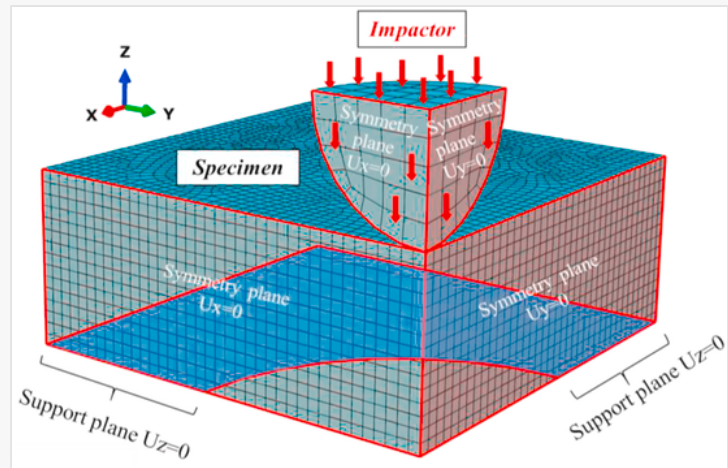

FE mesh and boundary conditions of the impactor and the specimen.

\section{Comparisons}

Numerical analysis results were compared with the experimental ones, to verify the accuracy of the numerical model in simulating the low velocity impact mechanical response of the considered materials. Four different types of 
measurements were compared, including force, energy, impactor penetration, and velocity along with the time of the experiment. Results for plain materials are presented in Fig. 17 and Fig. 18, whereas for the PVA-reinforced ones in Fig. 19 and Fig. 20.

alt-text: Fig. 17

\section{Fig. 17}
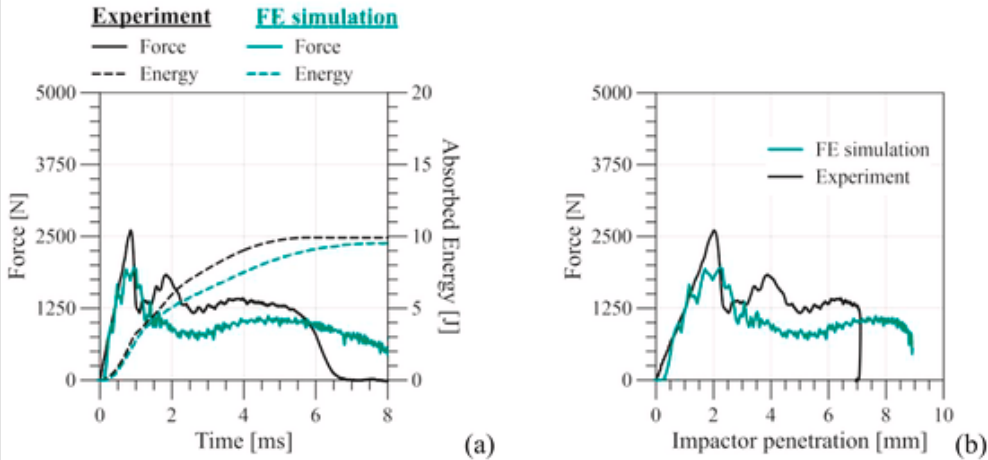

Comparison of experimental and numerical results for material 100-3: (a) force and energy vs. time; (b) force vs. impactor penetration.

alt-text: Fig. 18

Fig. 18

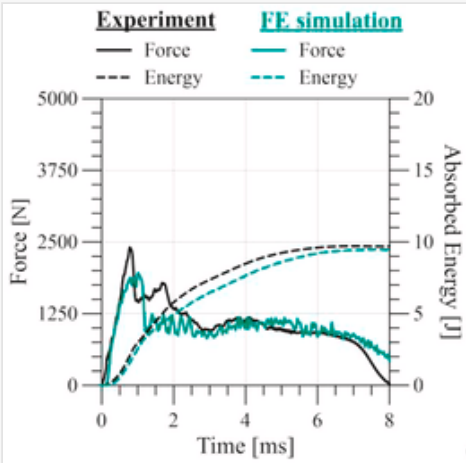

(a)

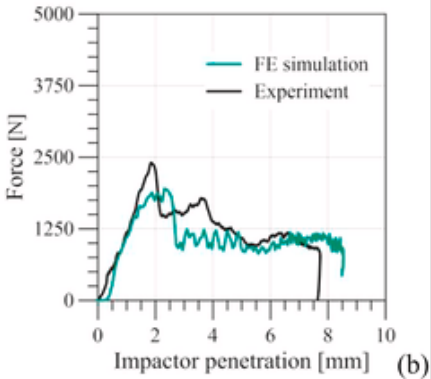

Comparison of experimental and numerical results for material 120-3: (a) force and energy vs. time; (b) force vs. impactor penetration.

alt-text: Fig. 19

Fig. 19

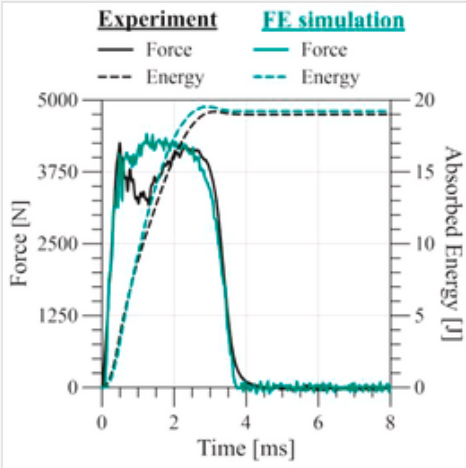

(a)

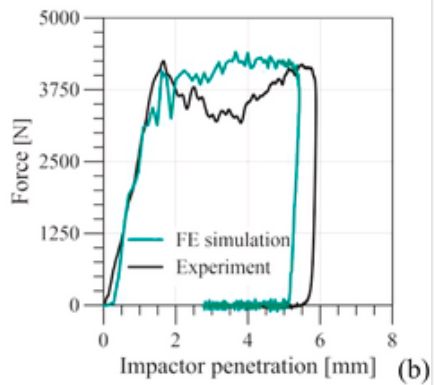

Comparison of experimental and numerical results for material PVA-100-3: (a) force and energy vs. time; (b) force vs. impactor penetration. 


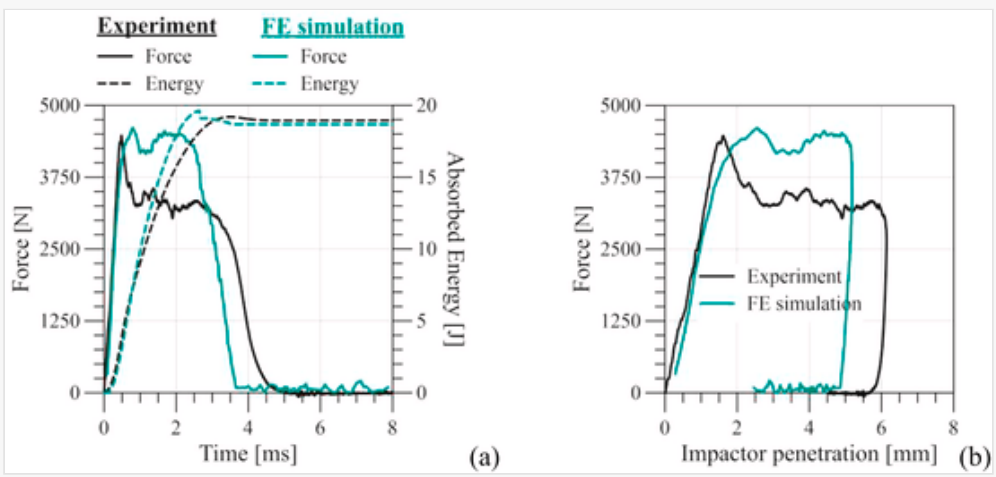

Comparison of experimental and numerical results for material PVA-120-3: (a) force and energy vs. time; (b) force vs. impactor penetration.

Outcomes of numerical simulation can be considered satisfactory having an overall good agreement with the experimental measurements. The main disagreements of the numerical model are for the behavior after the first force peak. With the actual input parameters for the post-peak material tensile law (Fig. 15), the numerical model could not accurately predict the second force peak of the unreinforced materials (see Figs. 17 and 18). Moreover, the inaccurate prediction is for the post first peak response of PVA reinforced materials (Figs. 19 and 20), which mainly depend on the load-carrying capacity of the fibers and their adhesion to matrix. Hence, considering the assumptions (adapted from models dedicated to steel fiber-reinforced concrete) and the approximations of the materials parameters, the CDP constitutive model certainly can predict the overall macroscopic impact response of all considered unreinforced and reinforced composites, with room for improvement on the post-peak response, when accurate experimental evidence is available for the tensile behavior of the materials. Comparing, in detail, the profile of the impacted surface along one line of symmetry (Fig. 16), the simulation overestimated the dent depth for both unreinforced materials, while estimated correctly its in-plane extension (Fig. 21a). It was the same for the PVA reinforced composites (Fig. 21b), for which the numerical model predicted a more accurate dent depth, as well. The obtained numerical results demonstrated the capacity of the model to predict, to some extent, the low-velocity impact performance of the considered materials. The accuracy of the numerical model can be improved having in mind the assumption on the material mechanical behavior, which was not supported by experimental measurements of some materials' parameters, namely tensile behavior and fracture energy.

alt-text: Fig. 21

\section{Fig. 21}
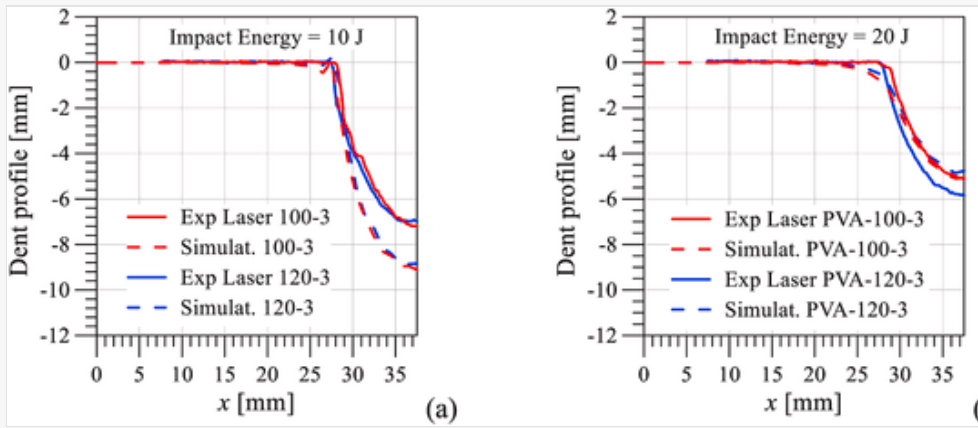

(a)

(b)

Comparison of representative experimental and numerical results of the impact surface profile along one line of symmetry: (a) unreinforced materials 100-3 and 120-3, impact energy $10 \mathrm{~J}$; (b) reinforced materials PVA-100-3 and PVA-120-3 impact energy $20 \mathrm{~J}$.

\section{Conclusions}

The study addressed the understanding of the impact performance of hot-pressed high-performance PVA fiber reinforced cementitious composites from alkali-activated stone wool. The oven produced composite counterpart was also considered for the sake of comparison. 
The twofold aim of this study is summarized according to the outcomes of the experimental measurements and the accuracy of the numerical predictions.

The main experimental understandings, by measurements during impact and after-impact, were:

- The PVA fibers drastically improved the impact response of the alkali-activated stone wool composite in both fabrication processes.

- The oven-cured and the $120{ }^{\circ} \mathrm{C}$ hot-pressed composites had the proper curing, which led to a strong interaction of the PVA fibers and the matrix, reflected as a better impact performance mainly of the hotpressed at $120^{\circ} \mathrm{C}$.

The proposed numerical model, adapting an available constitutive behavior, is suitable to predict the low-velocity impact response of the unreinforced and reinforced alkali-activated materials, although a better accuracy is expected having the measurements of the complete set of required material parameters. This mechanical model is, however, a proper numerical tool to have accurate prediction of the static and dynamic behavior of these hot-pressed composites for further developments and real applications.

Overall, it was shown the efficiency of the hot-pressing procedure in producing alkali-activated materials with similar or enhanced impact performance comparing to the conventional oven-curing. The present study confirms that hot-press production of alkali-activated composites can potentially enable a pathway for the on-demand production of a wide range of construction applications (e.g., prefabricated sandwich panels) having in mind the shorter processing time, improved physical and mechanical features, and the lower released $\mathrm{CO}_{2}$ emission than the oven-cured materials [4].

\section{Declaration of competing interest}

The authors declare that they have no known competing financial interests or personal relationships that could have appeared to influence the work reported in this paper.

\section{Acknowledgments}

This work was done as a part of FLOW (project number: 8904/31/2017) project funded by Business Finland in the ERA-MIN 2 Innovation program, which is part of the EU Horizon 2020 program. P. Kinnunen acknowledges financial support from Academy of Finland (grants no. 322085, 329477 and 326291). N. Ranjbar has received funding from the EU Horizon 2020 research and innovative program under the Marie Sklodowska-Curie (grant no. 713683). The authors gratefully acknowledge Samppa Hyvärinen for help during lab work, and Prof. Roberto Frassine for the fruitful discussions.

\section{References}

(i) The corrections made in this section will be reviewed and approved by a journal production editor. The newly added/removed references and its citations will be reordered and rearranged by the production team.

[1] Ranjbar N., Mehrali M., Maheri M.R., Mehrali M., Hot-pressed geopolymer, Cem. Concr. Res. 100 (2017) 14-22, doi:10.1016/j.cemconres.2017.05.010.

[2] Ranjbar N., Kashefi A., Maheri M.R., Hot-pressed geopolymer: dual effects of heat and curing time, Cem. Concr. Compos. 86 (2018) 1-8, doi:10.1016/j.cemconcomp.2017.11.004.

[3] Ranjbar N., Kashefi A., Ye G., Mehrali M., Effects of heat and pressure on hot-pressed geopolymer, Constr. Build. Mater. 231 (2020) 117106, doi:10.1016/j.conbuildmat.2019.117106.

[4] Nguyen H., Kaas A., Kinnunen P., Carvelli V., Monticelli C., Yliniemi J., Illikainen M., Fiber reinforced alkali-activated stone wool composites fabricated by hot-pressing technique, Mater. Des. 186 (2020) 108315, doi:10.1016/j.matdes.2019.108315. 
Yazıcı Ş., Arel H.Ş., Tabak V., The effects of impact loading on the mechanical properties of the SFRCs, Constr. Build. Mater. 41 (2013) 68-72, doi:10.1016/j.conbuildmat.2012.11.095.

[6] Taner Yildirim S., Ekinci C.E., Findik F., Properties of hybrid fiber reinforced concrete under repeated impact loads, Russ. J. Nondestruct. Test. 46 (2010) 538-546, doi:10.1134/S1061830910070090.

[7] Meng Q., Wu C., Su Y., Li J., Liu J., Pang J., Experimental and numerical investigation of blast resistant capacity of high performance geopolymer concrete panels, Compos. Part B Eng. 171 (2019) 9-19, doi:10.1016/j.compositesb.2019.04.010.

[8] Wang B., Chen Y., Fan H., Jin F., Investigation of low-velocity impact behaviors of foamed concrete material, Compos. Part B Eng. 162 (2019) 491-499, doi:10.1016/j.compositesb.2019.01.021.

[9] Feng J., Gao X., Li J., Dong H., Yao W., Wang X., Sun W., Influence of fiber mixture on impact response of ultra-high-performance hybrid fiber reinforced cementitious composite, Compos. Part B Eng. 163 (2019) 487-496, doi:10.1016/j.compositesb.2018.12.141.

[10] Ramakrishna G., Sundararajan T., Impact strength of a few natural fibre reinforced cement mortar slabs: a comparative study, Cem. Concr. Compos. 27 (2005) 547-553, doi:10.1016/j.cemconcomp.2004.09.006.

[11] Gupta T., Sharma R.K., Chaudhary S., Impact resistance of concrete containing waste rubber fiber and silica fume, Int. J. Impact Eng. 83 (2015) 76-87, doi:10.1016/j.ijimpeng.2015.05.002.

[12] Toutanji H., McNeil S., Bayasi Z., Chloride permeability and impact resistance of polypropylene-fiberreinforced silica fume concrete, Cem. Concr. Res. 28 (1998) 961-968, doi:10.1016/S00088846(98)00073-8.

[13] Siddique R., Properties of concrete incorporating high volumes of class F fly ash and san fibers, Cem. Concr. Res. 34 (2004) 37-42, doi:10.1016/S0008-8846(03)00192-3.

[14] Yoo D.-Y., Banthia N., Impact resistance of fiber-reinforced concrete - a review, Cem. Concr. Compos. 104 (2019) 103389, doi:10.1016/j.cemconcomp.2019.103389.

[15] Ranjbar N., Zhang M., Fiber-reinforced geopolymer composites: a review, Cem. Concr. Compos. 107 (2020) 103498, doi:10.1016/j.cemconcomp.2019.103498.

[16] ISO 13320:2020, Particle Size Analysis - Laser Diffraction Methods, International Organization for Standardization, 2020.

[17] Sahmaran M., Lachemi M., Hossain K.M.A., Ranade R., Li V.C., Influence of aggregate type and size on ductility and mechanical properties of engineered cementitious composites, ACI Mater. J. 106 (2009), doi:10.14359/56556.

[18] Flynn J.H., Polymer degradation, Handb. Therm. Anal. Calorim., Elsevier, 2002, pp. 587-651, doi:10.1016/S1573-4374(02)80017-6.

[19] Bhatti A.Q., Kishi N., Mikami H., Ando T., Elasto-plastic impact response analysis of shear-failure-type RC beams with shear rebars, Mater. Des. 30 (2009) 502-510, doi:10.1016/j.matdes.2008.05.068.

[20] Li P.P., Sluijsmans M.J.C., Brouwers H.J.H., Yu Q.L., Functionally graded ultra-high performance cementitious composite with enhanced impact properties, Compos. Part B Eng. 183 (2020) 107680, doi:10.1016/j.compositesb.2019.107680.

[21] Xu B., Toutanji H.A., Gilbert J., Impact resistance of poly(vinyl alcohol) fiber reinforced highperformance organic aggregate cementitious material, Cem. Concr. Res. 40 (2010) 347-351, doi:10.1016/j.cemconres.2009.09.006.

[22] Systèmes Dassault, Abaqus Software 6.14, Dassault Systèmes Simulia Corp., Providence, RI, USA, 2014. 
[23] Brannon R.M., Leelavanichkul S., Survey of Four Damage Models for Concrete, 2009, doi:10.2172/993922.

[24] Saini D., Shafei B., Concrete constitutive models for low velocity impact simulations, Int. J. Impact Eng. 132 (2019) 103329, doi:10.1016/j.ijimpeng.2019.103329.

[25] Sadraie H., Khaloo A., Soltani H., Dynamic performance of concrete slabs reinforced with steel and GFRP bars under impact loading, Eng. Struct. 191 (2019) 62-81, doi:10.1016/j.engstruct.2019.04.038.

[26] Abdel-Kader M., Modified settings of concrete parameters in RHT model for predicting the response of concrete panels to impact, Int. J. Impact Eng. 132 (2019) 103312, doi:10.1016/j.ijimpeng.2019.06.001.

[27] Fib, Fib Model Code for Concrete Structures 2010: FIB MODEL CODE 2010 O-BK, Wiley-VCH Verlag GmbH \& Co. KGaA, Weinheim, Germany, 2013, doi:10.1002/9783433604090.

[28] Carmona Malatesta S., Aguado de Cea A., Molins Borrell C., Generalization of the Barcelona test for the toughness control of FRC, Mater. Struct. 45 (2012) 1053-1069, doi:10.1617/s11527-011-9816-8.

[29] Hammitt G.M. II, Concrete Strength Relationships, U.S. Army Engineer Waterways Experiment Station, Soils end Pavements Laboratory, Vicksburg, 1974. https://erdc-library.erdc.dren.mil/jspui/bitstream/1168

\section{Queries and Answers}

\section{Q1}

Query: Please confirm that the provided emails “valter.carvelli@polimi.it, mirja.illikainen@oulu.fi” are the correct address for official communication, else provide an alternate e-mail address to replace the existing one, because private e-mail addresses should not be used in articles as the address for communication.

Answer: Addresses are correct

\section{Q2}

Query: Have we correctly interpreted the following funding source(s) you cited in your article: FLOW; Business Finland in the ERA-MIN 2 Innovation program; EU Horizon 2020 program; Academy of Finland; EU Horizon 2020 research and innovative program?

Answer: Yes

\section{Q3}

Query: Please confirm that given names and surnames have been identified correctly and are presented in the desired order and please carefully verify the spelling of all authors' names.

Answer: Yes

\section{Q4}

Query: Your article is registered as a regular item and is being processed for inclusion in a regular issue of the journal. If this is NOT correct and your article belongs to a Special Issue/Collection please contact n.thandavamoorthy@elsevier.com immediately prior to returning your corrections.

Answer: Yes 
